\title{
Evaluation of the effect of MTNR1B rs10830963 gene variant on the therapeutic efficacy of nateglinide in treating type 2 diabetes among Chinese Han patients
}

\author{
Jin-Fang Song ${ }^{1 \dagger}$, Jie Zhang ${ }^{2 \dagger}$, Ming-Zhu Zhang ${ }^{3}$, Jiang Ni ${ }^{1}$, Tao Wang ${ }^{4}$, Yi-Qing Zhao ${ }^{1 *}$ and Naveed Ullah Khan $^{5^{*}}$
}

\begin{abstract}
Genetic polymorphisms in the MTNR1B gene is associated with type 2 diabetes mellitus (T2DM); however, there is no evidence about its impact on the therapeutic efficacy of nateglinide. This prospective case-control study was designed to investigate the effect of MTNR1B rs10830963 gene variant on the therapeutic efficacy of nateglinide in treating T2DM. We genotyped untreated T2DM patients $(N=200)$ and healthy controls $(N=200)$ using the method of the high resolution of melting curve (HRM). Newly diagnosed T2DM patients $(n=60)$ with CYP2C9*1 and SLCO1B1 $521 T T$ genotypes were enrolled and given oral nateglinide $(360 \mathrm{mg} / \mathrm{d}$ ) for 8 weeks. The outcome was measured by collecting the venous blood samples before and at the 8 th week of the treatment. The risk $\mathrm{G}$ allelic frequency of MTNR1B rs 10830963 was higher in T2DM patients than the healthy subjects $(P<0.05)$. Post 8-week of treatment, newly diagnosed T2DM patients showed a less reduction in fasting plasma glucose levels and less increase in the carriers of genotype CG + GG at rs 10830963 when compared with the CC genotype $(P<0.05)$. MTNR1B rs 10830963 polymorphism was associated with the therapeutic efficacy of nateglinide in T2DM patients. Also, the CC homozygotes had a better effect than $\mathrm{G}$ allele carriers.
\end{abstract}

Trial registration Chinese Clinical Trial Register ChiCTR13003536, date of registration: May 14, 2013.

Keywords: MTNR1B rs10830963, Genetic variant, Nateglinide, Type 2 diabetes

\section{Introduction}

Type 2 diabetes mellitus (T2DM) is a chronic genetic heterogeneous disease with multiple genes and multiple environmental factors. In order to effectively control the glycemic level and to reduce the risk of secondary damage to cardiovascular, cerebrovascular, kidney and other organs, most patients with T2DM require treatment with

\footnotetext{
*Correspondence: 13813454165@126.com; naveedkhan1676@hotmail.com †Jin-Fang Song and Jie Zhang have contributed equally

${ }^{1}$ Department of Pharmacy, Affiliated Hospital of Jiangnan University, No.1000, Hefeng Road, Wuxi 214000, China

${ }^{5}$ Department of Pharmaceutics, College of Pharmaceutical Sciences,

Soochow University, Suzhou, Jiangsu, China

Full list of author information is available at the end of the article
} 
each individual $[2,3]$. The mechanism of the difference in the efficacy and adverse effects of nateglinide remains unclear. It is thought to vary based on the genetic conditions of the drug transporters, drug-metabolizing enzymes, drug receptors, and T2DM susceptibility genes [3]. There are a few types of research that attribute this difference may be due to the genetic polymorphisms of cytochrome P450 2C9 (CYP2C9) and genetic polymorphism in the SLCO1B1 gene encoding organic anion transporting polypeptide 1B1 (OATP1B1) [4]. It is found that due to the genetic polymorphism of the enzymes mentioned above and their impact on the pharmacokinetic process of nateglinide might contribute to the difference in the efficacy. But, this could not elucidate the complete mechanism of action by which the same nateglinide therapy results in various therapeutic responses [5-7].

In pharmacodynamics, the onset of nateglinide is rapid but with a shorter duration of action, compared with sulfonylureas. Thus it is able to significantly reduce postprandial hyperglycemia as well as improve glycemic control in T2DM $[8,9]$. In addition, other reports also showed that nateglinide had a good effect on improving insulin resistance [10-12]. Therefore, it is understood that genetic polymorphisms affecting insulin resistance or islet cell function may impact the efficacy of nateglinide treatment on T2DM patients. Hence it is important to study the effect of genetic variation on individual differences in the efficacy of nateglinide drugs for guiding clinical rational drug use and optimizing T2DM treatment strategies.

Three genome-wide association studies (GWAS) among the European populations conducted during the recent years have found that MTNR1B gene mutations have an association with the increased risk of T2DM, increased fasting plasma glucose (FPG), and decreased insulin secretion [13-15]. Among the observed risk variants, MTNR1B rs10830963(C>G) was the most strongly associated one with FPG [15]. Subsequently, it was also confirmed that MTNR1B rs10830963 had an association with increased FPG and increased risk of T2DM in Chinese Han population [16, 17]. Further, pharmacogenomic studies have shown that variants in genes associated with insulin secretion and insulin sensitivity, such as KCNQ1, SLC30A8, SLC22A1, TCF7L2 and NOS1AP gene variants, may affect T2DM patients' responsiveness to hypoglycemic drugs [18-21].

As aforementioned, the biological function of the MTNR1B gene and the therapeutic effect of nateglinide are mainly focused on the regulation of insulin secretion and resistance. However, whether the efficacy of nateglinide gets affected by the MTNR1B gene variant remains unclear. Thus, in this study, MTNR1B rs10830963 gene was selected as a genetic marker and the effect of MTNR1B gene variant on the therapeutic efficacy of nateglinide in Chinese type 2 diabetes patients is determined.

\section{Materials and methods Study design and participants}

This prospective case-control study included 200 unrelated T2DM patients (111 men and 89 women) and 200 healthy controls (99 men and 101 women) for analysis of MTNR1B rs10830963 gene variant. The T2DM patients and the healthy subjects were enrolled from the Department of Endocrinology and the Health Screening Center of the Affiliated Hospital of Xuzhou Medical College respectively. In the present study, the inclusion criteria for the control subjects were: (1) normal glucose tolerance as assessed by a standard $75 \mathrm{~g}$ OGTT (FPG $<6.1 \mathrm{mmol} / \mathrm{L}, \mathrm{PPG}<7.8 \mathrm{mmol} / \mathrm{L}$ ); and (2) no family history of diabetes indicated in a standard questionnaire. Diagnosis of T2DM was carried out based on the 1999 World Health Organization (WHO) criteria for hyperglycemia under the following conditions: FPG $>7.0 \mathrm{mmol} / \mathrm{L}$ or postprandial plasma glucose $(\mathrm{PPG})>11.1 \mathrm{mmol} / \mathrm{L}$. Exclusion criteria consisted of hypoglycemic drugs treatment, pregnancy or lactation, and the presence of serious diseases such as acute myocardial infarction, cerebral vascular accident, trauma, and kidney or liver diseases. All patients received a standard diabetes curriculum with a specific focus on diet, exercise and drug treatment compliance (Additional file 1).

A total of 60 newly diagnosed and unrelated T2DM patients (36 men and 24 women) with the same CYP2C9*1 and SLCO1B1 521TT genotypes were recruited for analysis of MTNR1B rs10830963 gene variant. They were subjected to detailed interviews and rigorous evaluations, including medication history. Patients who had not taken melatonin were included. Due to the close relationship between melatonin and $M T N R 1 B$, it is also necessary to exclude patients receiving this drug. All patients were asked to take $360 \mathrm{mg}$ nateglinide per day (120 mg before each meal) orally for eight consecutive weeks. They were also advised of the same standard of diet control and exercise therapy. Inclusion criteria: (1) Newly diagnosed and unrelated T2DM patients, (2) with a body mass index (BMI) of $18.5-30 \mathrm{~kg} / \mathrm{m}^{2}$. Exclusion criteria: (1) Have been treated with hypoglycemic drugs, (2) Those who had received agonists or inhibitors of CYP2C8, CYP2C9, CYP3A4 and SLCO1B1 treatment in recent 3 months, and (3) Patients who had received melatonin.

This study was registered in the Chinese Clinical Trial Register (No. ChiCTR13003536) and obtained approval from the ethics committee of the Affiliated Hospital of 
Xuzhou Medical College and followed the Helsinki Declaration II. Written informed consent was obtained from each participant before the study.

\section{Genotyping analysis}

SiMax Genome DNA Kit (Sbsbio, Shanghai, China) was used to isolate the genomic DNA from the peripheral blood leucocytes. High resolution of melting curve (HRM) method was used to analyze the MTNR1B rs10830963 gene variant. Following primer pairs were used for the analyses: 5'-GAGGATTTGCTTGCT GAACA-3' (forward) and 5'-CCCAGGCAGTTACTG GTTCT-3' (reverse). The total HRM reaction system for detecting MTNR1B gene mutation was $20 \mu \mathrm{L}$, including $10 \mu \mathrm{L}$ of HRM MasterMix buffer, $2.4 \mu \mathrm{L}$ of $\mathrm{Mg}^{2+}(25 \mathrm{mmol} / \mathrm{L}), 0.4 \mu \mathrm{L}$ of each of the forward and reverse primers $(10 \mathrm{mmol} / \mathrm{L})$, and $5 \mu \mathrm{L}$ of $\mathrm{DNA}(2 \mathrm{mg} / \mathrm{L})$ and water was added to $20 \mu \mathrm{L}$. Cycle parameters: $95{ }^{\circ} \mathrm{C}$ for $10 \mathrm{~min}, 95{ }^{\circ} \mathrm{C}$ for $10 \mathrm{~s}, 65^{\circ} \mathrm{C}$ for $15 \mathrm{~s}, 72{ }^{\circ} \mathrm{C}$ for $15 \mathrm{~s}$, a total of 55 cycles. Melting: $95^{\circ} \mathrm{C} 1 \mathrm{~min}, 40^{\circ} \mathrm{C} 1 \mathrm{~min}, 70^{\circ} \mathrm{C}$ $1 \mathrm{~s}, 95{ }^{\circ} \mathrm{C} 1 \mathrm{~min}$. Cooling: $40{ }^{\circ} \mathrm{C} 30 \mathrm{~s}$. Polymerase chain reaction-restriction fragment length gene variant (PCRRFLP) was used for genotyping of $C Y P 2 C 9$ gene variant and the four primer pairs used include forward primer: 5'-TGCACGAGGTCCAGAGATGC-3', reverse primer: 5'-CTATGAATTTGGGGACTTCG-3'. Amplification refractory mutation system (ARMS) was used to detect the SLCO1B1 T521C genotypes and the four primer pairs used include: forward primer: 5'-AAGTAGTTAAAT TTGTAATAGAAATGC- $3^{\prime}$, reverse primer: $5^{\prime}$-GTAGAC AAAGGGAAAGTGATCATA-3'; forward primer for TT genotype: 5'-GGGTCATACATGTGGATATAAGT$3^{\prime}$, reverse primer for mutant variants: 5'-AAGCATATT ACCCATGAACG-3'. 2\% agarose gel electrophoresis was used to separate the obtained DNA fragments followed by ethidium bromide staining and visualization with UV transillumination.

\section{Clinical laboratory tests}

Blood samples were collected from participants in fasting state (fasting for more than $8 \mathrm{~h}$ ) and $2 \mathrm{~h}$ after breakfast respectively. $100 \mathrm{~g}$ of sugar-free steamed bread was provided for standard breakfast. Body parameters that included body height, body mass index (BMI), waist circumference, hip circumference, systolic blood pressure (SBP), and diastolic blood pressure (DBP) were measured before and at 8 weeks of treatment respectively. BMI was calculated as weight $(\mathrm{kg}) /$ height $(\mathrm{m})^{2}$. Waist-toHip Ratio (WHR) was calculated as waistline $(\mathrm{cm}) /$ hipline $(\mathrm{cm})$. Clinical indicators were also detected before and at 8 weeks after the administration of nateglinide. Roche Cobas 8000 analyzer (Roche, Basel, Switzerland) was used to detect the plasma glucose, serum lipids triglycerides (TG), total cholesterol (TC), low-density cholesterol (LDL-c) and high-density cholesterol (HDLc) with standard laboratory methods. Electro-chemiluminescence assay (Roche, Shanghai China) was used to measure insulin levels. High-performance liquid chromatography (HPLC) was used to determine the amounts of glycated hemoglobin $\left(\mathrm{HbA}_{1 \mathrm{c}}\right)$. Homeostasis model assessment for insulin resistance (HOMA-IR) and islet $\beta$ cell function (HOMA- $\beta$ ) was calculated using the formula: HOMA-IR $=$ fasting insulin $(\mathrm{mU} / \mathrm{L}) \times$ fasting plasma glucose $(\mathrm{mmol} / \mathrm{L}) / 22.5$ and HOMA- $\beta=20 \times$ FINS $(\mathrm{mU} / \mathrm{L}) /$ [FPG $(\mathrm{mmol} / \mathrm{L})-3.5]$ respectively.

\section{Statistical analysis}

Statistical analyses were performed with SPSS 18.0 software (SPSS, Chicago, IL, USA). The Hardy-Weinberg equilibrium, allelic frequencies in different groups, and categorical variables (counting data) were assessed using the Pearson chi-square test. All continuous variables were expressed as mean \pm standard deviation (mean $\pm S D$ ). The paired Student's $t$-test was used to compare all the parameters between the two groups before and after nateglinide treatment. The two-sample $t$ test or one-way ANOVA test were used for comparison between the two groups for the parameters of normal distribution. Parameters with abnormal distribution were analyzed by the Kruskal-Wallis test. Statistical power calculations were performed using a power calculator software PASS (www.ncss.com). A value of $P<0.05$ was considered statistically significant.

\section{Results}

\section{Allelic frequency analysis}

A total of 200 T2DM patients (111 men and 89 women) and 200 healthy subjects ( 99 men and 101 women) were genotyped for MTNR1B rs10830963 gene variant. The genotype distribution in each group was consistent with the Hardy-Weinberg equilibrium $(P>0.05)$. The allele frequencies of the MTNR1B rs10830963 gene variant in T2DM patients and healthy subjects are given in Table 1 . The frequency of the MTNR1B rs10830963 G allele was higher in T2DM patients when compared to the healthy subjects $(42.50 \%$ vs $34.50 \%, P<0.05)$.

\section{Assessment of baseline parameters with different MTNR1B rs 10830963 genotypes in T2DM patients}

The baseline clinical characteristics of T2DM patients with different MTNR1B rs10830963 genotypes were analyzed in Table 2 . No association was observed between MTNR1B rs10830963 gene variant and sex, age, BMI, WHR, PPG, fasting serum insulin (FINS), postprandial serum insulin (PINS), HOMA-IR, HbA1c, TG, TC, HDL-c, and LDL-c. 
Table 1 Comparison of genotype and frequencies of MTNR1B rs10830963 polymorphism between T2DM patients and healthy subjects

\begin{tabular}{llll}
\hline Genotypes & $\begin{array}{l}\text { Healthy subjects } \\
(\mathbf{n = 2 0 0})\end{array}$ & $\begin{array}{l}\text { T2DM patients } \\
(\mathbf{n}=\mathbf{2 0 0})\end{array}$ & $\boldsymbol{P}$ value \\
\hline \multicolumn{2}{l}{ MTNR1B rs10830963 } & & \\
CC & $82(41.00 \%)$ & $70(35.00 \%)$ & \\
CG & $98(49.00 \%)$ & $90(45.00 \%)$ & \\
GG & $20(10.00 \%)$ & $40(20.00 \%)$ & $0.019^{\Delta *}$ \\
Alleles & & & \\
C & $262(65.50 \%)$ & $230(57.50 \%)$ & \\
G & $138(34.50 \%)$ & $170(42.50 \%)$ & $0.020^{\Delta *}$ \\
\hline
\end{tabular}

The allelic frequencies are indicated in absolute values (percentage). ${ }^{\Delta} P$ values are determined by the Pearson chi-square test. ${ }^{*} P<0.05$

Table 2 The baseline characteristics in T2DM patients with various MTNR1B rs10830963 genotypes before treatment with nateglinide $(n=200)$

\begin{tabular}{lllll}
\hline Parameters & \multicolumn{2}{l}{ MTNR1B rs10830963 genotype } & \multirow{2}{*}{ P value } \\
\cline { 2 - 4 } & CC & CG & GG & \\
\hline N (men/women) & $70(40 / 30)$ & $90(48 / 42)$ & $40(23 / 17)$ & $0.850^{\Delta}$ \\
Age (years) & $47.81 \pm 10.82$ & $48.01 \pm 12.04$ & $47.09 \pm 13.92$ & 0.921 \\
BMI (kg/m²) & $26.41 \pm 3.24$ & $25.43 \pm 3.31$ & $26.59 \pm 4.11$ & 0.104 \\
WHR & $0.92 \pm 0.06$ & $0.91 \pm 0.06$ & $0.92 \pm 0.08$ & $0.552^{\#}$ \\
FPG (mmol/L) & $9.61 \pm 2.01$ & $9.91 \pm 2.79$ & $10.82 \pm 1.79$ & $0.034^{*}$ \\
PPG (mmol/L) & $15.36 \pm 2.46$ & $14.21 \pm 4.39$ & $14.69 \pm 5.71$ & 0.224 \\
FINS (mU/L) & $8.56 \pm 5.39$ & $7.37 \pm 6.99$ & $7.53 \pm 6.39$ & $0.477^{\#}$ \\
PINS (mU/L) & $30.01 \pm 17.10$ & $28.11 \pm 20.51$ & $33.51 \pm 17.49$ & 0.320 \\
HOMA-IR & $3.27 \pm 1.30$ & $3.09 \pm 3.21$ & $4.01 \pm 2.47$ & 0.160 \\
HbA1c (\%) & $9.71 \pm 1.97$ & $9.11 \pm 2.62$ & $9.95 \pm 2.04$ & 0.098 \\
TG (mmol/L) & $2.25 \pm 1.38$ & $2.31 \pm 2.13$ & $1.97 \pm 1.52$ & 0.596 \\
TC (mmol/L) & $5.21 \pm 1.29$ & $4.99 \pm 1.31$ & $5.49 \pm 1.51$ & 0.143 \\
HDL-c (mmol/L) & $1.28 \pm 0.95$ & $1.33 \pm 0.59$ & $1.41 \pm 0.29$ & 0.645 \\
LDL-c (mmol/L) & $3.45 \pm 0.68$ & $3.61 \pm 1.19$ & $3.80 \pm 0.93$ & $0.199^{\#}$ \\
\hline
\end{tabular}

$B M I$ body mass index, WHR waist to hip ratio, FPG fasting plasma glucose, $P P G$ postprandial plasma glucose, FINS fasting serum insulin, PINS postprandial serum insulin, HOMA-IR homeostasis model assessment for insulin resistance, $H b A_{1 c}$ hemoglobin $A_{1,} T G$ triglyceride, TC total cholesterol, $H D L-c$ high-density lipoprotein-cholesterol, $L D L$-c low-density lipoprotein-cholesterol

Data are given as (mean $\pm \mathrm{SD}$ ). $P$ values represent statistical differences among the three different genotypes by the one-way ANOVA. ${ }^{\Delta} P$ values are determined by the Pearson chi-square test. ${ }^{\#} P$ values are determined by the Kruskal-Wallis test. ${ }^{*} P<0.05$

However, FPG, $(9.61 \pm 2.01 \mathrm{mmol} / \mathrm{L}$ for CC genotype, $9.91 \pm 2.79 \mathrm{mmol} / \mathrm{L}$ for $\mathrm{CG}$ and $10.82 \pm 1.79 \mathrm{mmol} / \mathrm{L}$ for GG, respectively; $P<0.05$, Fig. 1 ) showed significant differences.
Effects of MTNR1B rs10830963 gene variant on the efficacy of nateglinide in T2DM patients

T2DM patients $(\mathrm{n}=60)$ with different MTNR1B rs10830963 but the same SLCO1B1 521TT and CYP2C9*1 genotypes were randomly selected to participate in our study to avoid the potential impacts of SLCO1B1 and CYP2C9 genetic polymorphisms. It was observed that these patients responded to nateglinide therapy. After 8 weeks of treatment, they showed a remarkable decline in the level of FPG, PPG, $\mathrm{HbA}_{1 \mathrm{c}}$ and TC (all $P<0.05$ ), but significant increase in the levels of FINS, PINS and HOMA- $\beta$ (all $P<0.05$ ). The comparison with the pretreatment values was tabulated in Table 3.

Since the GG genotype frequency was lower in the selected population, we combined the CG genotype (26 cases) and the GG genotype (8 cases) for analysis and compared with the CC genotype (26 cases). After nateglinide treatment, the FPG value of the patients with genotypes CG and GG was higher, when compared with the carriers of genotype CC. PINS and HOMA- $\beta$ values were lower, when compared with the $\mathrm{CC}$ genotype carriers $(P<0.05)$. T2DM patients with genotype CC at MTNR1B rs10830963 had a significant decrease in FPG $(\mathrm{mmol} / \mathrm{L})$ when compared with the genotypes CG and GG $(-3.75 \pm 1.68$ vs $-2.87 \pm 1.32 ; P<0.05)$ respectively. In addition, the carriers of genotype $C C$ at MTNR1B rs10830963 had higher differential values of HOMA- $\beta$, when compared with the genotypes CG and GG $(40.87 \pm 23.52$ vs $25.13 \pm 19.21 ; P<0.05)$ respectively (Table 4, Fig. 2).

\section{Discussion}

In this study, the gene variant of MTNR1B rsl0830963 potentially influenced the efficacy of nateglinide in Chinese patients with T2DM. We observed this in T2DM patients with G allele of MTNR1B rs10830963 decreased the efficacy of nateglinide. We also found that the risk $\mathrm{G}$ allelic frequency of MTNR1B rsl0830963 was significantly higher in T2DM patients than healthy subjects $(P<0.05)$. Consequently, MTNR1B gene represents a susceptibility target for T2DM and affects the response to nateglinide.

A significant basis for clinical individualized drug delivery is provided by a relatively new subject called pharmacogenomics. Presently, the pharmacogenomics researches of oral hypoglycemic drugs mainly focus on the study of classic sulfonylurea oral hypoglycemic agents, thiazolidinedione insulin sensitizers and biguanide hypoglycemic drugs. There are few reports on the pharmacogenomics of the novel insulin secretagogues of glinide, but no evidence related to MTNR1B gene is found. 

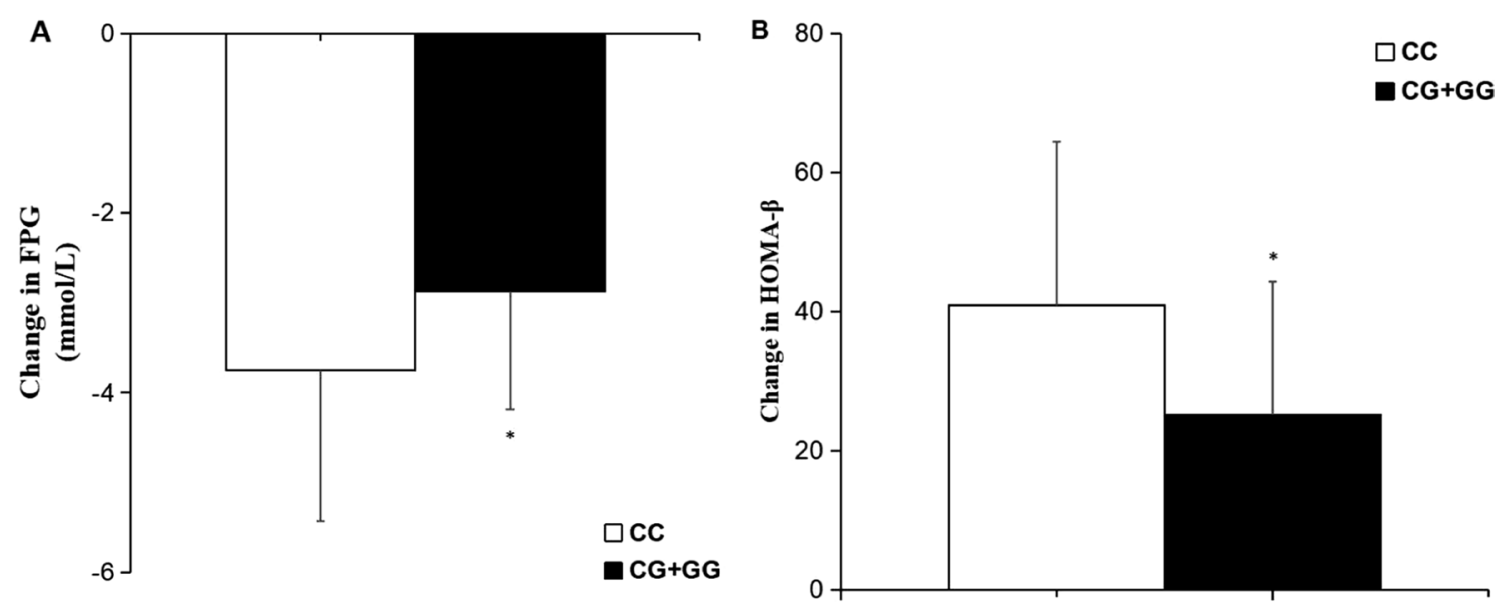

Fig. 1 Baseline levels of FPG in T2DM patients with different MTNR1B rs 10830963 genotypes. Data are expressed as (mean \pm SD). ${ }^{*} P<0.05$ compared with CC genotype group

Table 3 Clinical characteristics of T2DM patients before and after nateglinide treatment $(n=60)$

\begin{tabular}{lccc}
\hline Parameters & Before treatment $\mathbf{n}=\mathbf{6 0}$ & After treatment $\mathbf{n}=\mathbf{6 0}$ & $\boldsymbol{P}$ values \\
\hline BMI $\left(\mathrm{kg} / \mathrm{m}^{2}\right)$ & $25.41 \pm 3.54$ & $25.33 \pm 3.11$ & 0.896 \\
WHR & $0.92 \pm 0.06$ & $0.91 \pm 0.06$ & 0.363 \\
FPG (mmol/L) & $10.41 \pm 1.23$ & $7.25 \pm 1.21$ & $0.000^{*}$ \\
PPG (mmol/L) & $14.56 \pm 2.76$ & $9.38 \pm 2.61$ & $0.000^{*}$ \\
FINS (mU/L) & $7.56 \pm 4.39$ & $9.51 \pm 3.46$ & $0.008^{*}$ \\
PINS (mU/L) & $30.31 \pm 17.10$ & $47.21 \pm 15.16$ & $0.000^{*}$ \\
HOMA-IR & $3.57 \pm 1.30$ & $2.72 \pm 1.41$ & $0.001^{*}$ \\
HOMA- $\beta$ & $25.73 \pm 14.5$ & $60.32 \pm 21.15$ & $0.000^{*}$ \\
HbA1c (\%) & $9.31 \pm 1.87$ & $7.89 \pm 0.81$ & $0.000^{*}$ \\
TG (mmol/L) & $2.25 \pm 1.38$ & $1.86 \pm 1.23$ & 0.105 \\
TC (mmol/L) & $5.21 \pm 1.29$ & $4.31 \pm 1.09$ & $0.000^{*}$ \\
HDL-c (mmol/L) & $1.38 \pm 0.75$ & $1.45 \pm 0.59$ & 0.571 \\
LDL-c (mmol/L) & $3.85 \pm 1.78$ & $3.42 \pm 1.07$ & 0.111
\end{tabular}

$B M I$ body mass index, WHR waist to hip ratio, FPG fasting plasma glucose, PPG postprandial plasma glucose, FINS fasting serum insulin, PINS postprandial serum insulin, HOMA-IR homeostasis model assessment for insulin resistance, HOMA- $\beta$ Homeostasis model assessment for islet $\beta$ cell function, HbA1c hemoglobin A1c, TG triglyceride, TC total cholesterol, $H D L$-c high-density lipoprotein-cholesterol, $L D L$ - $c$ low-density lipoprotein-cholesterol

Data are expressed as (mean \pm SD). $P$ values are determined by the paired Student's $t$ test. ${ }^{*} P<0.05$

Studies conducted with the Chinese Han population have confirmed that single nucleotide gene variants (SNPs) of MTNR1B are associated with T2DM susceptibility [22, 23]. Among the SNP sites involved in MTNR1B, the rs10830963 locus is a functional polymorphic locus and is closely related to glucose metabolism and islet $\beta$ cell function. Further, it is highly correlated with the pathogenesis of T2DM. The variation of the MTNR1B gene is consistent with the FPG level; rs10830963 is the most relevant, and each G allele increases the FPG level by $0.07 \mathrm{mmol} / \mathrm{L}$. The homeostasis model assessment (HOMA- $\beta$ ) analysis showed impaired beta-cell function [15]. In this study, we found that the risk G allelic frequency of MTNR1B rsl0830963 was significantly higher in T2DM patients, when compared to the healthy subjects $(P<0.05)$ and remains consistent with previous studies $[15,16]$. The study had an estimated $80-92 \%$ power (for $\alpha=0.05$ ) to detect such a difference in allelic frequencies and genotypes distribution. Also, it is found that patients with T2DM carrying the GG genotype had higher FPG levels when compared with the CC and CG genotypes. The difference being statistically significant, suggest that the $\mathrm{G}$ allele has an association with the elevated FPG levels.

The pineal gland releases the circulating hormone melatonin (MLT) and its action is mediated by melatonin 
Table 4 Effects of different MTNR1B rs10830963 genotypes in T2DM patients on clinical traits determined before and after nateglinide treatment

\begin{tabular}{|c|c|c|c|}
\hline Parameters & $C C(n=26)$ & $C G(n=26)+G G(n=8)$ & $P$ value \\
\hline $\mathrm{N}$ (male/female) & $26(16 / 10)$ & $34(20 / 14)$ & $0.902^{\Delta}$ \\
\hline \multicolumn{4}{|l|}{ FPG (mmol/L) } \\
\hline Before & $10.73 \pm 2.05$ & $10.81 \pm 1.92$ & 0.877 \\
\hline After & $6.98 \pm 1.35$ & $7.94 \pm 1.23$ & $0.006^{*}$ \\
\hline DV & $-3.75 \pm 1.68$ & $-2.87 \pm 1.32$ & $0.027^{*}$ \\
\hline \multicolumn{4}{|l|}{ PPG (mmol/L) } \\
\hline Before & $14.51 \pm 4.31$ & $13.04 \pm 4.72$ & 0.220 \\
\hline After & $9.34 \pm 3.24$ & $9.27 \pm 3.49$ & 0.937 \\
\hline DV & $-5.17 \pm 4.08$ & $-3.77 \pm 3.19$ & $0.141^{\#}$ \\
\hline \multicolumn{4}{|l|}{ FINS (mU/L) } \\
\hline Before & $8.82 \pm 6.81$ & $7.80 \pm 4.20$ & 0.478 \\
\hline After & $10.18 \pm 6.60$ & $9.32 \pm 3.64$ & 0.522 \\
\hline DV & $1.36 \pm 4.10$ & $1.84 \pm 3.80$ & 0.641 \\
\hline \multicolumn{4}{|l|}{ PINS (mU/L) } \\
\hline Before & $31.42 \pm 20.47$ & $27.47 \pm 16.43$ & 0.410 \\
\hline After & $48.41 \pm 19.78$ & $37.13 \pm 20.87$ & $0.038^{*}$ \\
\hline DV & $16.99 \pm 17.82$ & $9.66 \pm 19.37$ & 0.138 \\
\hline \multicolumn{4}{|l|}{ HOMA-IR } \\
\hline Before & $4.48 \pm 2.88$ & $3.24 \pm 1.73$ & 0.066 \\
\hline After & $3.39 \pm 2.12$ & $2.43 \pm 1.18$ & 0.072 \\
\hline DV & $-0.89 \pm 1.93$ & $-0.79 \pm 1.31$ & 0.704 \\
\hline \multicolumn{4}{|l|}{ HOMA- $\beta$} \\
\hline Before & $27.75 \pm 16.03$ & $24.08 \pm 17.32$ & 0.405 \\
\hline After & $68.62 \pm 45.21$ & $49.21 \pm 24.36$ & $0.037^{*}$ \\
\hline DV & $40.87 \pm 23.52$ & $25.13 \pm 19.21$ & $0.006^{*}$ \\
\hline \multicolumn{4}{|l|}{$\mathrm{HbA} 1 \mathrm{c}(\%)$} \\
\hline Before & $9.79 \pm 1.86$ & $9.15 \pm 2.26$ & $0.246^{\#}$ \\
\hline After & $7.00 \pm 0.84$ & $7.01 \pm 1.05$ & 0.968 \\
\hline DV & $-2.79 \pm 1.53$ & $-2.14 \pm 1.74$ & 0.137 \\
\hline \multicolumn{4}{|l|}{ TG (mmol/L) } \\
\hline Before & $2.46 \pm 1.96$ & $2.31 \pm 1.90$ & 0.766 \\
\hline After & $2.21 \pm 1.91$ & $1.79 \pm 1.23$ & 0.306 \\
\hline DV & $-0.25 \pm 1.95$ & $-0.52 \pm 1.58$ & $0.096^{\#}$ \\
\hline \multicolumn{4}{|l|}{$\mathrm{TC}(\mathrm{mmol} / \mathrm{L})$} \\
\hline Before & $5.27 \pm 1.69$ & $5.22 \pm 1.15$ & $0.892^{\#}$ \\
\hline After & $4.84 \pm 1.12$ & $4.89 \pm 1.37$ & $0.880^{\#}$ \\
\hline DV & $-0.43 \pm 1.53$ & $-0.33 \pm 1.09$ & $0.769^{\#}$ \\
\hline \multicolumn{4}{|l|}{ HDL-c (mmol/L) } \\
\hline Before & $1.42 \pm 0.51$ & $1.47 \pm 0.47$ & $0.695^{\#}$ \\
\hline After & $1.35 \pm 0.55$ & $1.43 \pm 0.51$ & $0.563^{\#}$ \\
\hline DV & $-0.07 \pm 0.68$ & $-0.04 \pm 0.46$ & 0.839 \\
\hline \multicolumn{4}{|l|}{ LDL-c (mmol/L) } \\
\hline Before & $3.28 \pm 1.19$ & $3.18 \pm 1.05$ & $0.731^{\#}$ \\
\hline After & $3.19 \pm 1.20$ & $3.11 \pm 1.07$ & 0.786 \\
\hline DV & $-0.09 \pm 1.26$ & $-0.07 \pm 1.08$ & 0.948 \\
\hline
\end{tabular}

$B M I$ body mass index, WHR waist to hip ratio, FPG fasting plasma glucose, $P P G$ postprandial plasma glucose, FINS fasting serum insulin, PINS postprandial serum insulin, HOMA-IR homeostasis model assessment for insulin resistance HOMA- $\beta$ Homeostasis model assessment for islet $\beta$ cell function, $H b A 1 c$
Table 4 (continued)

hemoglobin A1c, TG triglyceride, TC total cholesterol, $H D L-c$ high-density lipoprotein-cholesterol, $L D L$-c low-density lipoprotein-cholesterol, DV differential values (post-administration minus pre-administration)

Data are given as (mean $\pm \mathrm{SD}$ ). ${ }^{\Delta} P$ values are determined by the Pearson chisquare test. ${ }^{~} P$ values are determined by the Kruskal-Wallis test. ${ }^{*} P<0.05$

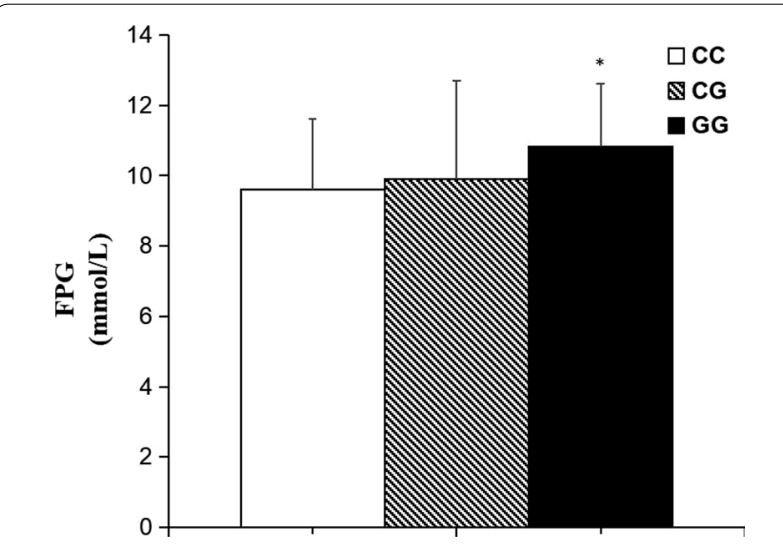

Fig. 2 Comparisons of differential values (pre-administration levels subtracted from the post-administration levels) of FPG (A) and HOMA- $\beta$ (B) between different MTNR1B rs10830963 genotypes in T2DM patients before and after treatment of nateglinide. Data are expressed as (mean \pm SD). ${ }^{*} P<0.05$ compared with CC genotype group respectively

receptor 1 and 2 (MT1, MT2) respectively. MT2 is encoded by the MTNR1B gene and is expressed in the islet beta cells of both animals and human beings [13]. Multiple GWAS studies conducted in European populations found that MTNR1B rs10830963 is associated with FPG, insulin secretion, and T2DM susceptibility $[14,15]$. Subsequently, it was also found that MTNR1B rs10830963 has an association with FPG and islet $\beta$-cell function in Chinese Han population [16, 17]. However, the molecular mechanism by which the MTNR1B gene variant increases T2DM susceptibility remains unclear. Studies have reported that after MLT activates MT2, MT2 gets coupled with the inhibitory G protein, mediating cAMP and cGMP signal transduction pathways and inhibits insulin release from islet beta cells [22, 23]. In addition to MLT in MT2 knockout mice, islet $\beta$ cells release insulin increases [24] and therefore MTNR1B gene variant increased T2DM susceptibility relating to its influence on insulin secretion.

Next to repaglinide, nateglinide is the new non-sulfonylurea oral hypoglycemic agent. It is more commonly used in clinical practices, but the difference in efficacy and adverse reactions is significant. The main mechanism of action of nateglinide is to close the ATP-dependent $\mathrm{K}^{+}$channel on the islet $\beta$-cell membrane to cause the 
depolarization of the cell membrane and open the $\mathrm{Ca}^{2+}$ channel to lead to $\mathrm{Ca}^{2+}$ influx and thus promote insulin secretion [25]. Therefore, the MTNR1B gene variant plays a role in the hypoglycemic effect of nateglinide.

The purpose of this study was to analyze the effect of MTNR1B rs10830963 gene variant on the efficacy of nateglinide in treating the newly diagnosed type 2 diabetes patients. Previous studies have reported that $C Y P 2 C 9$ and SLCO1B1 gene variants may affect the pharmacokinetics of nateglinide [26-29]. Hence we decided to retain the same patients with the CYP2C9*1 and SLCO1B1 521TT genotypes as subjects to rule out interference. After 8 consecutive weeks of nateglinide monotherapy, patients with FPG, PPG, FINS, PINS, HOMA-IR, HOMA- $\beta$, HbA1c, and TC showed significant improvement. This suggested that nateglinide has a good therapeutic effect on patients with type 2 diabetes. There are literatures reporting the nateglinide effect on improving insulin resistance $[10,11]$. Our research results were found to be consistent with the literature results. But, there was no evidence to find the relationship between MTNR1B rs10830963 gene variant and nateglinide efficacy. Therefore, in our study, we compared the difference between the clinical indicators before and after nateglinide treatment. The decrease of FPG and the increase of HOMA- $\beta$ in MTNR1B rs10830963 risk gene $\mathrm{G}$ carriers were lower when compared with the CC genotype patients $(P<0.05)$. These results indicated that the risk gene $\mathrm{G}$ carriers had a worse response to nateglinide when compared with the CC genotype patients. Also, the clinical treatment showed that the GG genotype patient had poor nateglinide treatment. Prokopenko et al [15] reported that calculation of islet beta-cell function using the homeostasis model showed that, MTNR1B rs10830963 risk gene $\mathrm{G}$ carriers had lower islet function. Lyssenko et al. [14] found "in" GG homozygotes, oral or intravenous glucose stimulation early-phase insulin release was impaired. Previous reports results were consistent with the results of this study. After nateglinide treatment, risk gene G may further reduce the efficacy of nateglinide by affecting FPG and HOMA- $\beta$. The exact mechanism by which the $M T N R 1 B$ gene variant affects the efficacy of nateglinide requires further investigation.

However, this study does have some shortcomings as the sample size is not large enough, and the frequency of MTNR1B rs10830963 GG genotype is low. Therefore, this study might miss some meaningful results. Hence, we recommend further detailed study with expanded sample size. Glinide drugs are mealtime blood glucose regulators and are characterized by rapid but short-acting insulin secretion with weak hypoglycemic effect and good safety. Therefore, this study neither focused on the clinical adverse events during nateglinide monotherapy nor did it receive reports of adverse events in the subjects. T2DM is a multi-gene metabolic disease and in this study we found that the MTNR1B gene variant has a certain effect on the efficacy of nateglinide. But the individual difference in the efficacy of hypoglycemic drugs is caused by the accumulation of multiple gene variants as well as the changes in the environmental factors and lifestyles. The results of a single genetic polymorphism study could not fully explain the individual differences in drug efficacy. Patients received only an 8-week course of nateglinide therapy, and optimal reduction in HbA1c levels occurs after 12 weeks of administration [30]. Therefore, in order to apply this research results to clinical practice, it requires collaboration among researchers from different regions.

In summary, the results of this study suggest that the MTNR1B rs10830963 gene variant is associated with the efficacy of nateglinide in the treatment of type 2 diabetes, and also has a certain role in promoting clinical individualized drug delivery. Finally, the statistical power of our study may be sufficient had we collected a relatively larger sample size. We recommend exploration with more extensive and comprehensive clinical research along with an in-depth mechanism to confirm its relevance.

\section{Conclusion}

In conclusion, we report for the first time that $M T N R 1 B$ rs10830963 gene variant might influence the incidence of T2DM among the Chinese Han population and the efficacy of nateglinide monotherapy. The $\mathrm{CC}$ homozygotes had a better effect than $\mathrm{G}$ allele carriers. Genetic, environmental and disease factors may be the important reasons for individual differences in drug efficacy. Genetic pharmacology mainly studies the influence of genetic factors on individual differences in drug efficacy, which provides the basis for further mechanism exploration and clinical individualized drug administration. With in-depth studies about genetic contributors to diabetes treatment response, it is more likely that the management of diabetes disease will be at the forefront of translating exploratory research into clinical practice in some situations. Indeed, further pharmacogenetic and functional investigations are required to determine the effect of MTNR1B variants on nateglinide therapeutic efficacy and to lay the foundation for patient-tailored therapy.

\section{Abbreviations}

HRM: High resolution of melting curve; T2DM: Type 2 diabetes mellitus; FPG: Fasting plasma glucose; GWAS: Genome-wide association studies; WHO: World Health Organization; BMI: Body mass index; PCR-RFLP: Polymerase chain reaction-restriction fragment length polymorphism; ARMS: Amplification refractory mutation system; SBP: Systolic blood pressure; DBP: Diastolic blood pressure; WHR: Waist-to-hip ratio; TG: Triglycerides; TC: Total cholesterol; LDL-c: Low-density cholesterol; HDL-c: High-density cholesterol; HPLC: 
High-performance liquid chromatography; HbA1c: Glycated hemoglobin; HOMA-IR: Homeostasis model assessment for insulin resistance; HOMA- $\beta$ : Homeostasis model assessment for islet $\beta$ cell function; FINS: Fasting serum insulin; PINS: Postprandial serum insulin.

\section{Supplementary Information}

The online version contains supplementary material available at https://doi. org/10.1186/s12920-021-01004-y.

Additional file 1. Dietarycontrol compliance assessment form.

\section{Acknowledgements}

We thank all the volunteers in this study for their cooperation, and the physicians from the Department of Endocrinology, the Affiliated Hospital of Xuzhou Medical College for their support.

\section{Authors' contributions}

J-FS designed all the work under the supervision of Y-QZ. Y-QZ and NUK designed the research, contributed substantially with data analysis, results interpretations and manuscript editing and approval. M-ZZ, JZ, JN and TW collected the patients' data and did Gene analysis. All authors read and approved the final manuscript.

\section{Funding}

This work was supported by the Hospital Pharmaceutical Research Project of Jiangsu Pharmaceutical Association and Tianqing (No. Q2019096), Wuxi Science and Technology Development Medical and Health Guidance Project (No. CSZON1809), Jiangsu Research Hospital Association for Precision Medication (JY202011) and Wuxi Science and Technology Association Key Soft Science Research Project (No. KX-18-D24). The authors declare that they have no financial relationship with the organization that sponsored the research, and the funding body was not involved in study design, data collection, analysis and writing of the study.

\section{Availability of data and materials}

The datasets generated and analyzed during the current study are available in the link"https://submit.ncbi.nlm.nih.gov/subs/variation_file/SUB9598166/ overview". The accession number is SUB9598166.

\section{Declarations}

\section{Ethics approval and consent to participate}

Manuscript reporting studies involving human participants, human data or human tissue are reported with approved statement on ethics approval and consent under registration ChiCTR-CCC-13003536.

\section{Consent for publication}

Not Applicable.

\section{Competing interests}

The authors declare that they have no conflicts of interest.

\section{Author details \\ 'Department of Pharmacy, Affiliated Hospital of Jiangnan University, No.1000, Hefeng Road, Wuxi 214000, China. ${ }^{2}$ School of Pharmacy, Wannan Medical College, Wuhu, China. ${ }^{3}$ Department of Pharmacy, Shandong Province Third Hospital, Jinan 250000, China. ${ }^{4}$ Department of Endocrinology, Affiliated Hospital of Xuzhou Medical College, Xuzhou 221000, China. ${ }^{5}$ Department of Pharmaceutics, College of Pharmaceutical Sciences, Soochow University, Suzhou, Jiangsu, China.}

Received: 18 February 2021 Accepted: 1 June 2021

Published online: 12 June 2021

\section{References}

1. Stumvoll M, Goldstein BJ, van Haeften TW. Type 2 diabetes: principles of pathogenesis and therapy. Lancet. 2005;365:1333-46. https://doi.org/10. 1016/s0140-6736(05)61032-X.

2. Cai $X L$, Luo YY, Han XY, Ji LN. A meta-analysis of efficacy and safety of nateglinide in type 2 diabetes mellitus in Asia. Chin J Diabetes. 2012;21:913-7.

3. Cheng Y, Xiong QX, Liu Q, Zhu ZG, Guo XY. A comparative study of the clinical efficacy of Naglinide and Acarbose in the treatment of type 2 diabetes mellitus. Mod Chin Drug Use. 2010;4:166-7.

4. Kalliokoski A, Neuvonen M, Neuvonen PJ, Niemi M. Different effects of SLCO1B1 polymorphism on the pharmacokinetics and pharmacodynamics of repaglinide and nateglinide. J Clin Pharmacol. 2008;48:311-21. https://doi.org/10.1177/0091270007311569.

5. Barroso I, Luan J, Middelberg RP, Harding AH, Franks PW, Jakes RW, et al. Candidate gene association study in type 2 diabetes indicates a role for genes involved in beta-cell function as well as insulin action. PLoS Biol. 2003;1:E20. https://doi.org/10.1371/journal.pbio.0000020.

6. Schwanstecher C, Meyer U, Schwanstecher M. K(IR)6.2 polymorphism predisposes to type 2 diabetes by inducing overactivity of pancreatic beta-cell ATP-sensitive K(+) channels. Diabetes. 2002;51:875-9. https:// doi.org/10.2337/diabetes.51.3.875.

7. Barhanin J, Lesage F, Guillemare E, Fink M, Lazdunski M, Romey G. K(V) LQT1 and IsK (minK) proteins associate to form the I(Ks) cardiac potassium current. Nature. 1996;384:78-80. https://doi.org/10.1038/384078a0.

8. Calles-Escandon J, Robbins DC. Loss of early phase of insulin release in humans impairs glucose tolerance and blunts thermic effect of glucose. Diabetes. 1987;36:1167-72. https://doi.org/10.2337/diab.36.10.1167.

9. Keilson L, Mather S, Walter YH, Subramanian S, McLeod JF. Synergistic effects of nateglinide and meal administration on insulin secretion in patients with type 2 diabetes mellitus. J Clin Endocrinol Metab. 2000;85:1081-6. https://doi.org/10.1210/jcem.85.3.6446.

10. Hazama Y, Matsuhisa M, Ohtoshi K, Gorogawa S, Kato K, Kawamori D, et al. Beneficial effects of nateglinide on insulin resistance in type 2 diabetes. Diabetes Res Clin Pract. 2006;71:251-5. https://doi.org/10.1016/j.diabres. 2005.08.004.

11. Shiba T. Improvement of insulin resistance by a new insulin secretagogue, nateglinide-analysis based on the homeostasis model. Diabetes Res Clin Pract. 2003;62:87-94.

12. Kudo-Fujimaki $K$, Hirose $T$, Yoshihara T, Sato F, Someya $Y$, Ohmura C, et al. Efficacy and safety of nateglinide plus vildagliptin combination therapy compared with switching to vildagliptin in type 2 diabetes patients inadequately controlled with nateglinide. J Diabetes Investig. 2014;5:400-9. https://doi.org/10.1111/jdi.12160.

13. Bouatia-Naji N, Bonnefond A, Cavalcanti-Proenca C, Sparso T, Holmkvist J, Marchand M, et al. A variant near MTNR1B is associated with increased fasting plasma glucose levels and type 2 diabetes risk. Nat Genet 2009;41:89-94. https://doi.org/10.1038/ng.277.

14. Lyssenko V, Nagorny CL, Erdos MR, Wierup N, Jonsson A, Spegel P, et al. Common variant in MTNR1B associated with increased risk of type 2 diabetes and impaired early insulin secretion. Nat Genet. 2009;41:82-8. https://doi.org/10.1038/ng.288.

15. Prokopenko I, Langenberg C, Florez JC, Saxena R, Soranzo N, Thorleifsson $\mathrm{G}$, et al. Variants in MTNR1B influence fasting glucose levels. Nat Genet. 2009;41:77-81. https://doi.org/10.1038/ng.290.

16. Kan MY, Zhou DZ, Zhang D, Zhang Z, Chen Z, Yang YF, et al. Two susceptible diabetogenic variants near/in MTNR1B are associated with fasting plasma glucose in a Han Chinese cohort. Diabetes Med. 2010;27:598-602. https://doi.org/10.1111/j.1464-5491.2010.02975.x.

17. Liu C, Wu Y, Li H, Qi Q, Langenberg C, Loos RJ, et al. MTNR1B rs 10830963 is associated with fasting plasma glucose, $\mathrm{HbA} 1 \mathrm{C}$ and impaired beta-cell function in Chinese Hans from Shanghai. BMC Med Genet. 2010;11:59. https://doi.org/10.1186/1471-2350-11-59.

18. Schroner $Z$, Javorsky M, Kozarova M, Tkac I. Pharmacogenetics of oral antidiabetic treatment. Bratisl Lek Listy. 2011;112:441-6.

19. Chen M, Hu C, Jia W. Pharmacogenomics of glinides. Pharmacogenomics. 2015;16:45-60. https://doi.org/10.2217/pgs.14.152.

20. Florez JC. Pharmacogenetics in type 2 diabetes: precision medicine or discovery tool? Diabetologia. 2017;60:800-7. https://doi.org/10.1007/ s00125-017-4227-1. 
21. Pearson ER. Pharmacogenetics and target identification in diabetes. Curr Opin Genet Dev. 2018;50:68-73. https://doi.org/10.1016/j.gde.2018.02. 005.

22. Peschke E, Bach AG, Muhlbauer E. Parallel signaling pathways of melatonin in the pancreatic beta-cell. J Pineal Res. 2006;40:184-91. https://doi. org/10.1111/j.1600-079X.2005.00297.x.

23. Stumpf I, Bazwinsky I, Peschke E. Modulation of the CGMP signaling pathway by melatonin in pancreatic beta-cells. J Pineal Res. 2009;46:140-7. https://doi.org/10.1111/j.1600-079X.2008.00638.x.

24. Muhlbauer E, Gross E, Labucay K, Wolgast S, Peschke E. Loss of melatonin signalling and its impact on circadian rhythms in mouse organs regulat ing blood glucose. Eur J Pharmacol. 2009;606:61-71. https://doi.org/10. 1016/j.ejphar.2009.01.029.

25. Dornhorst A. Insulinotropic meglitinide analogues. Lancet. 2001;358:1709-16. https://doi.org/10.1016/s0140-6736(01)06715-0.

26. Kirchheiner J, Meineke I, Muller G, Bauer S, Rohde W, Meisel C, et al. Influence of CYP2C9 and CYP2D6 polymorphisms on the pharmacokinetics of nateglinide in genotyped healthy volunteers. Clin Pharmacokinet. 2004;43:267-78. https://doi.org/10.2165/00003088-200443040-00005.

27. Cheng Y, Wang G, Zhang W, Fan L, Chen Y, Zhou HH. Effect of CYP2C9 and SLCO1B1 polymorphisms on the pharmacokinetics and pharmacodynamics of nateglinide in healthy Chinese male volunteers. Eur J Clin Pharmacol. 2013;69:407-13. https://doi.org/10.1007/s00228-012-1364-9.
28. Niemi M, Backman JT, Kajosaari LI, Leathart JB, Neuvonen M, Daly AK, et al. Polymorphic organic anion transporting polypeptide $1 \mathrm{~B} 1$ is a major determinant of repaglinide pharmacokinetics. Clin Pharmacol Ther. 2005;77:468-78. https://doi.org/10.1016/j.clpt.2005.01.018.

29. Izumi S, Nozaki Y, Maeda K, Komori T, Takenaka O, Kusuhara H, et al. Investigation of the impact of substrate selection on in vitro organic anion transporting polypeptide 1B1 inhibition profiles for the prediction of drug-drug interactions. Drug Metab Dispos. 2015;43:235-47. https:// doi.org/10.1124/dmd.114.059105

30. Gong ZC, Huang Q, Dai XP, Lei GH, Lu HB, Yin JY, et al. NeuroD1 A45T and PAX4 R121W polymorphisms are associated with plasma glucose level of repaglinide monotherapy in Chinese patients with type 2 diabetes. $\mathrm{Br}$ J Clin Pharmacol. 2012;74:501-9. https://doi.org/10.1111/j.1365-2125.2012. 04202.x.

\section{Publisher's Note}

Springer Nature remains neutral with regard to jurisdictional claims in published maps and institutional affiliations.
Ready to submit your research? Choose BMC and benefit from:

- fast, convenient online submission

- thorough peer review by experienced researchers in your field

- rapid publication on acceptance

- support for research data, including large and complex data types

- gold Open Access which fosters wider collaboration and increased citations

- maximum visibility for your research: over $100 \mathrm{M}$ website views per year

At BMC, research is always in progress.

Learn more biomedcentral.com/submissions 